ENTREPRENEURSHIP AND SUSTAINABILITY ISSUES

ISSN 2345-0282 (online) http://jssidoi.org/jesi/

2021 Volume 9 Number 1 (September)

http://doi.org/10.9770/jesi.2021.9.1(27)

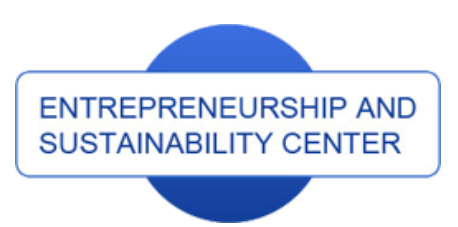

Publisher

$\underline{\text { http://jssidoi.org/esc/home }}$
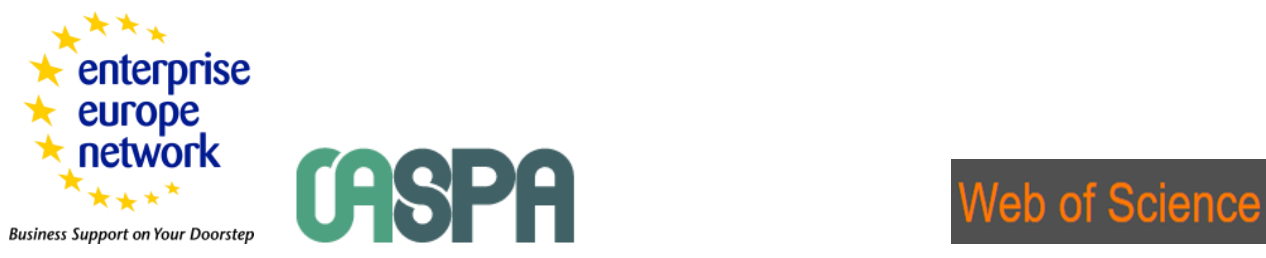

1) Clarivate

\title{
EFFICIENCY OF MANAGEMENT PROCESSES IN A PRIVATE HOSPITAL*
}

\author{
Dana Jašková \\ Faculty of Social and Economic Relations, Alexander Dubček University in Trenčín, Študentská 2, Trenčín, Slovak Republic \\ E-mail: dana.jaskova@tnuni.sk
}

Received 25 May 2021; accepted 16 July 2021; published 30 September 2021

\begin{abstract}
Efficiency, especially in the health care sector, has been a topical issue. The examination of the health care efficiency shows the extent to which the health care system inputs are efficiently used to provide health care services outputs. The purpose of the study is to analyse technical activities of twelve departments in a private hospital in the Slovak Republic. The data used were obtained from the statistical databases of 2019 - 2020. Activities were evaluated by using the Data Envelopment Analysis (DEA). DEA is a non-parametric method, which was designed to evaluate efficiency of production units. DEA can be used to analyse a large number of inputs and outputs with a multicriteria evaluation of variants. The BCC and CCR models, which aim to minimize inputs, were employed. In the empirical part of the study, DEA was utilised to identify technical efficiency of the hospital wards. In addition, the efficiency of transforming inputs into outputs using efficiency scores is compared and input optimizing options are given. In 2019 and 2020, the Department of Neonatology and Department of Surgery reported the best efficiency scores in both models. Following the analysis, reference rates for inefficient departments are given. In the next period, the hospital management is recommended to carry out continuous evaluations of the indicators by the model used for the needs of operational management.
\end{abstract}

Keywords: Efficiency; health service; DEA Model; Efficiency Score

Reference to this paper should be made as follows: Jašková, D. 2021. efficiency of management processes in a private hospital. Entrepreneurship and Sustainability Issues, 9(1), 436-446. http://doi.org/10.9770/jesi.2021.9.1(27)

JEL Classifications: C61, C89, I11

Additional disciplines: information and communication; mathematics; medicine

\section{Introduction}

Measuring and evaluating efficiency play an important role in managerial activities. The issue of evaluating efficiency and performance of production units in public and private sectors has always been a topical one in terms of the management practice needs. Efficiency assessment does not mean a mere a ranking of individual

\footnotetext{
* This work was supported by the Slovak Research and Development Agency under the contract No. APVV-19-0579.
} 


\section{ENTREPRENEURSHIP AND SUSTAINABILITY ISSUES}

ISSN 2345-0282 (online) http://jssidoi.org/jesi/

2021 Volume 9 Number 1 (September)

http://doi.org/10.9770/jesi.2021.9.1(27)

items, but a continuous analysis aimed to find the factors with the biggest impact on the efficient or inefficient behaviour of the units under observation. Such an analysis should lead to the elimination of sources of inefficiency and improve activities of the managed units. In general, unit efficiency is expressed as the ratio of desired outputs produced by the unit and inputs consumed by the unit in the production.

Recently, costs for hospitals have increased sharply in many countries. Although huge resources are allocated to healthcare services globally, there is a need to develop the available resources and ensure that they are used efficiently to increase productivity of hospitals. Population aging, high technology medical equipment, expectations of people and knowledge about their health status, and hospital inefficiencies in resource use are some of the reasons for rising health care costs (Yaisawarng, 2002). One way to reduce health care costs in hospitals is to evaluate their performance over time by measuring their productivity and efficiency. Efficient use of resources is one of the essential activities that hospital managements are engaged in. It is possible to evaluate units with multiple inputs and outputs without providing the information on prices through Data Envelopment Analysis (DEA) and Stochastic Frontier Analysis (SFA) (Kuntz et al., 2007). This way, efficiency of hospitals and their wards can be assessed. Concerning inpatient wards, two traditional inputs of labour and capital can be distinguished. In the case of hospitals, labour refers to medical staff while capital refers to costs, revenues, or average number of days that patients spend in hospitals. Since hospitals produce different outputs, and diagnoses and treatments vary between patients, the present study is limited to some extent.

The purpose of the study was to analyse and compare efficiency of hospital departments in order to help the managerial staff take right decisions, ensure optimal utilization of available resources, and optimize input costs using DEA.

\section{Theoretical background}

Data Envelopment Analysis (DEA) is a set of mathematical programming based models which evaluate the relative efficiencies of Decision-Making Units (DMUs) with multiple inputs and outputs (see Data Envelopment Analysis Online Software). Process efficiency has been discussed in scientific literature for a long time and its roots can be traced back to the existence of activity or work. The central issue in the debate on efficiency is how to achieve better results in the activities that we are performing with lower costs and less equipment, how to use the existing workforce to the fullest, and how to avoid wasting material and human capital.

Generally, there are operational and overall efficiency distinguished. Overall efficiency can be decomposed into technical efficiency, allocative efficiency, scale efficiency and assortment efficiency. Unlike allocative efficiency, technical efficiency does not require price data. Technical efficiency is defined as the ability of an entity to obtain the maximum amount of outputs at a given set of inputs, or the ability to reduce the amount of inputs at a given set of outputs (Grmanová, 2010). In the following text, the notion of efficiency will refer to technical efficiency.

Charnes et al. (1978) were first to introduce Data Envelopment Analysis as an optimization method of mathematical programming developed by Farrell (1957). Historically, it was Farrell who laid the foundations of the DEA method (1957). He measured unit efficiency using one input and one output. His model was extended by Charnes, Cooperr and Rhodes (1978) who are considered to be the authors of a complex multivariable model. Their model is referred to as the CCR model employing the assumption of constant returns to scale. Later, Banker, Charnes and Cooper (1984) extended this model with the variable returns to scale (VRS) assumption, which is known as BCC model. BCC model modifies the efficient frontier, and compared to CCR model, it is capable of identifying a bigger number of efficient production DMUs (Decision Making Units). Production DMUs can represent different levels of health care, such as national or regional healthcare services provided in hospitals or wards. When applying DEA, input-oriented or output-oriented models can be distinguished. Inputoriented models for shifting to the efficiency frontier do not require a change on the output side, but they examine 


\section{ENTREPRENEURSHIP AND SUSTAINABILITY ISSUES}

ISSN 2345-0282 (online) http://jssidoi.org/jesi/

2021 Volume 9 Number 1 (September)

http://doi.org/10.9770/jesi.2021.9.1(27)

what proportional reductions in inputs are required to achieve efficiency. On the other hand, output-oriented models answer the question of what maximum outputs can be achieved when employing the given number of inputs. Both models were used in the sector of healthcare.

The first studies on measuring hospital efficiency were conducted by Nunamakera (1983) and Scherman (1984). Nunamaker published a study on measuring the efficiency of the routine nursing services. Scherman, on the other hand, used DEA for calculating the overall hospital efficiency. In 2002, Andes et al. published a study using data on 115 health care units. He develops a model to help determine best practices of efficient physician offices while allowing for choices between inputs. They pointed to the fact that increasing the efficiency of these units is only possible if resources are better managed. Key works on efficiency evaluation of production units providing health care services were written by Banker et al. (1984), Linn (1998), Giuffrida and Gravelle (2001), Worthington (2004), Hollingsworth (2008). DEA has been increasingly used in the health care sector recently. Recent papers with major findings were published by Arya and Yadav (2018), Rubio and Diaz (2018), Kohl et al. (2019).

Input-oriented models are used by Czypionka et al. (2014). Hernandez and San Sebastian (2014) maintain that in the case of health care, inputs are uniform, their numbers are low, and health outcomes need to be increased. They also note that the inputs are often undersized and their reduction is not ethical. Cheng et al. (2016) justify the choice of an output-oriented model for the limited control of hospital managers due to the input limited legal standards. Oikonomou et al. (2016) also work with the output-oriented model because of the ever increasing demand for health care services. Even though they argue that the input reduction is questionable, it can be done when efficiency is evaluated objectively.

The next step in DEA is the choice of input and output variables. Input variables are the inputs that generate measurable outputs in the healthcare delivery process. They can be controlled and are directly linked to health services provided in hospitals. One of the commonly used input variables to compare hospitals is the number of hospital beds (Maniadakis and Thanassoulis, 2000; Barnum et al., 2011, Lacko et al., 2014; Stefko et al., 2018). Another input variable is the number of doctors and nurses. Sometimes, the total number of employees is taken as an input variable. The total number of staff, however, does not provide much information on the efficiency of health care services. Yet, the number of staff has an impact on rising wage costs. Cheng et al. (2016) divided the total number of employees into several categories and treated them as separate inputs. This input indicator has often been under discussion due to the recommendations on the input indicator reduction. Currently, the number of doctors and nurses is generally considered to be low, so these recommendations are considered to be unethical. Outputs are measurable indicators that reflect the level, i.e. the efficiency of input transformation to outputs in the health care services provided. The ideal healthcare output indicator should represent the level of health gained by individual patients. However, this is difficult to measure. Therefore, only measurable and reportable outputs can be used. The indicators of bed occupancy and hospital resources utilisation are often used in the literature (Belciug and Gorunescu, 2015; Dy et al., 2015). The authors note that low percentage of the total hospital beds utilised signal inefficient management of financial resources. Another frequently used output is the average treatment time. The average treatment time refers to the length of the patient's stay in hospitals (Varabyova and Schreyögg, 2013). Many works deal with external factors and their impact on the healthcare services, such as demographic, social, socio-economic and environmental factors (Varabyova and Schreyögg, 2013; Mura and Orlíková, 2016; Kočišová and Gavurová, 2019). Return on invested capital and various composite financial indicators (de Souza et al., 2014) are further examples of output indicators. The financial indicator of revenue, composed of several sub-indicators is also used as an output indicator in the present study.

Slovakia has been included in several cross-country studies comparing the performance of health care systems. In a study conducted by the OECD in the field of health, the Slovak Republic was found to perform inefficiently with a score of 0.90 (input-oriented DEA model) and 0.97 (output-oriented DEA model). The causes of this inefficiency were, however, not clearly identified. Cost-effectiveness of healthcare in Slovakia has remained low, 


\section{ENTREPRENEURSHIP AND SUSTAINABILITY ISSUES}

ISSN 2345-0282 (online) http://jssidoi.org/jesi/

2021 Volume 9 Number 1 (September)

http://doi.org/10.9770/jesi.2021.9.1(27)

hospitals are seeing considerable debt and there is a low occupancy of beds (Kališ, 2018). Stefko et al. (2018) measured the regional (NUTS 3) efficiency of healthcare facilities in Slovakia using the data envelopment analysis. The indicators they analysed were taken from official databases. Input variables were the number of beds, number of medical staff, number of CT (Computed Tomography devices) and number of medical equipment together. Output variables were the Bed occupancy rate and Average nursing time in days.

In the studies conducted in Slovakia, DEA was only used to compare efficiency of several hospitals. Thus, hospitals served as the production units. This is because the data needed to conduct DEA are not officially available. It is, however, more important for managerial decision-making to compare the efficiency of individual wards in one hospital.

\section{Research objective and methodology}

There are several approaches to evaluate the efficiency of production units, which differ in several attributes. Parametric and non-parametric methods can be distinguished. Parametric methods include the Stochastic Frontier Approach (SFA), Thick Frontier Approach (TFA) and Distribution Free Approach (DFA). DEA is a nonparametric method based on linear programming that estimates a marginal production function. The function is the maximum possible product based on a certain number of inputs. The function shapes are convex with no points below them (3). SFA is a parametric method based on econometric models and microeconomic theory. SFA uses a combination of data (panel data) to estimate the production (cost) function with regard to a hypothesis or statistical test.

DEA models can be radial or additive. Radial models encompass Envelopment Forms, Multiplier Forms, Scale Efficiency Measurement, and Models with Value Judgments. Moreover, there are also alternative models which can be used to develop super-efficiency models. New approaches to efficiency modelling include Range Directional Measurement, Variant of Radial Measure (Beta) and Cost Efficiency Models. Another category of DEA models are network models that evaluate efficiency of production units with parallel or serial structure (Jablonský, 2015). In the study, basic input-oriented radial CCR and BCC models, i.e. with constant (CRS) and variable (VRS) returns to scale, were utilised. DEA can be used to classify each DMU as efficient or inefficient, to incorporate inputs and outputs with different units of measures and treat them as comparable, and to identify optimal production and consumption values (Cesconetto et al., 2008).

General DEA models analyse technical efficiency of a set of production units (DMUs) that are characterised by $m$ inputs and $r$ outputs over the same period of time. The efficiency score $\theta_{q}$ of each $D M U_{q}$ is defined as weighted sum of outputs divided by the weighted sum of inputs by formulas (Jablonský, 2015):

$$
\theta_{q}=\frac{\sum_{k=1}^{r} w_{k} y_{k q}}{\sum_{i=1}^{m} v_{i} x_{i q}},
$$

where $w_{k}\left(w_{k}>0, k=1, \ldots, r\right)$ is weight of the $k$-th output, $v_{i}\left(v_{i}>0, i=1, \ldots, m\right)$ is weight of the $i$-th input, $x_{i q}$ and $y_{k q}$ are non-negative values for the $D M U_{q}$ of the $i$-th input and $k$-th output respectively. The variable $\theta_{q}$ can be interpreted as the required input reduction rate to reach the efficient frontier and its value is less than or equal to one (Jablonský and Dlouhý, 2004). General DEA models maximize the effective score relative to other production units. This problem is solved for each DMU, which means that $n$ optimization problems (LP optimization problems) are solved. The DMUs with $\theta_{q}=1$ are lying on the efficient frontier estimated by the model and denoted as efficient units. Otherwise, the units are inefficient and the efficiency score can be explained as a rate for reduction of inputs in order to reach the maximum efficiency in the future. When evaluating $D M U_{q}$, DEA model tries to find a virtual unit that is characterized by the inputs $\boldsymbol{X} \boldsymbol{\lambda}$ and outputs $\boldsymbol{Y} \boldsymbol{\lambda}$, which are a linear 
combination of the inputs and outputs in other analysed units and which are better than the inputs and outputs $D M U_{q} . \lambda=\left(\lambda_{1}, \ldots, \lambda_{n}\right)$ is a weight vector assigned to each unit and $\boldsymbol{X}(\boldsymbol{Y})$ are the input (output) matrices.

This cross-sectional study is both descriptive and analytical. The data was obtained from a private hospital in Slovakia that provides health care services which are covered by the patients' health insurance. The hospital is one of the major healthcare providers in the region. The hospital provides medical and preventive care to almost 110 thousand people of the population in the catchment area, and 600 thousand patients received cancer treatment. In 2020, the hospital had 576 employees. A total of 11,050 patients were hospitalized using 309 beds and 86,527 patients were given treatment as outpatients

The production units analysed were 12 inpatient wards in 2019 and 2020. The following indicators served as input data: the number of doctors, number of nurses and total costs. Items included in the costs were personnel costs, medicines, special medical supplies, maintenance, rent, indirect costs and other costs. Revenue was an output indicator used to evaluate the ward efficiency. Revenues included inpatient care reimbursement, other health insurance reimbursement, indirect and other earnings. It should be noted that the types of hospital admissions were different due to the pandemic in 2020 .

Input-oriented CCR and BCC models were used due to a single output variable. The research was carried out using various indicators in twelve hospital wards (DMU1) - Departments of Internal Medicine and Geriatrics, Neurology, Paediatrics, Gynecology and Obstetrics, Surgery, Clinical and Radiation Oncology, Anaesthesiology and Intensive Care, Neonatology, Long-term Sick, and Intensive Care Units: internal, neurology and surgery. The official numbers of doctors and nurses in 2019 and 2020 are given in the table 1 below.

Table 1. Selected analysed inputs

\begin{tabular}{|c|c|c|c|c|c|}
\hline & \multirow[t]{2}{*}{ Department } & \multicolumn{2}{|c|}{2019} & \multicolumn{2}{|c|}{2020} \\
\hline & & No. of doctors & No. of nurses & No. of doctors & No. of nurses \\
\hline 1 & Department of Internal Medicine and Geriatrics & 13 & 23 & 12 & 23 \\
\hline 2 & Department of Neurology & 8 & 15 & 6 & 14 \\
\hline 3 & Department of Paediatrics & 5 & 11 & 5 & 11 \\
\hline 4 & Department of Gynecology and Obstetrics & 11 & 16 & 11 & 16 \\
\hline 5 & Department of Surgery & 12 & 20 & 14 & 20 \\
\hline 6 & Department of Clinical and Radiation Oncology & 4 & 11 & 5 & 11 \\
\hline 7 & Department of Anaesthesiology and Intensive Care & 8 & 19 & 9 & 18 \\
\hline 8 & Department of Neonatology & 1 & 11 & 1 & 11 \\
\hline 9 & Intensive care unit - internal & 1 & 10 & 1 & 11 \\
\hline 10 & Intensive care unit - neurology & 1 & 5 & 2 & 4 \\
\hline 11 & Intensive care unit - surgery & 2 & 10 & 2 & 9 \\
\hline 12 & Department of the long-term sick & 2 & 8 & 2 & 8 \\
\hline
\end{tabular}


Costs were the next input variable. Costs are, however, not given in the study due to confidentiality reasons. DEA model was created by the Data Envelopment Analysis Online Software System (DEAOS).

\section{Results and discussion}

Based on the model formulation, calculations were performed using an optimization system for solving DEA models. The study analyses the efficiency of hospital wards by using two different input-oriented DEA models. Two basic radial models, such as Constant return to Scales and Variable Return to scales, were employed to carry out the research. The resulting efficiency scores for 2019 and 2020 are listed in Table 2.

Table 2. Efficiency scores of the hospital wards

\begin{tabular}{|c|c|c|c|c|c|c|c|}
\hline & \multirow[t]{3}{*}{$D M U$} & \multicolumn{3}{|c|}{ Model CCR-I (CRS) } & \multicolumn{3}{|c|}{ Model BCC-I (VRS) } \\
\hline & & \multicolumn{2}{|c|}{ Score efficiency (\%) } & \multirow[t]{2}{*}{ diff. } & \multicolumn{2}{|c|}{ Score efficiency $(\%)$} & \multirow[t]{2}{*}{ diff. } \\
\hline & & 2019 & 2020 & & 2019 & 2020 & \\
\hline 1 & Department of Internal Medicine and Geriatrics & 75,0 & 82,2 & 7,2 & 75,0 & 89,2 & 14,2 \\
\hline 2 & Department of Neurology & 72,8 & 93,8 & 21,0 & 80,3 & 94,0 & 13,7 \\
\hline 3 & Department of Pediatrics & 51,8 & 37,5 & $-14,3$ & 66,5 & 60,0 & $-6,5$ \\
\hline 4 & Department of Gynecology and Obstetrics & 74,3 & 86,1 & 11,8 & 80,2 & 89,5 & 9,3 \\
\hline 5 & Department of Surgery & 100 & 100 & 0,0 & 100 & 100 & 0,0 \\
\hline 6 & Department of Clinical and Radiation Oncology & 59,0 & 56 & $-3,0$ & 62,7 & 64,5 & 1,8 \\
\hline 7 & Department of Anesthesiology and Intensive Care & 45,6 & 54,7 & 9,1 & 53,9 & 61,1 & 7,2 \\
\hline 8 & Department of Neonatology & 100 & 100 & $\mathbf{0 , 0}$ & 100 & 100 & 0,0 \\
\hline 9 & Intensive care unit - internal & 57,7 & 53,9 & $-3,8$ & 100 & 100 & 0,0 \\
\hline 10 & Intensive care unit - neurology & 94,4 & 82,7 & $-11,7$ & 100 & 100 & 0,0 \\
\hline 11 & Intensive care unit - surgery & 46,9 & 48,5 & 1,6 & 65,1 & 83,9 & 18,8 \\
\hline \multirow[t]{2}{*}{12} & Department of the long - term sick & 98,3 & 100 & 1,7 & 100 & 100 & 0,0 \\
\hline & Average & 73,0 & 74,6 & 1,6 & 82,0 & 86,9 & 4,9 \\
\hline
\end{tabular}

Efficiency scores in 2019 and 2020 are given in the graph below. On the left-hand side, the efficient scores in CCR input models are listed. On the right-hand side, the efficient scores in BCC input model are shown in Figure 1. 
ENTREPRENEURSHIP AND SUSTAINABILITY ISSUES

ISSN 2345-0282 (online) http://jssidoi.org/jesi/ 2021 Volume 9 Number 1 (September) http://doi.org/10.9770/jesi.2021.9.1(27)

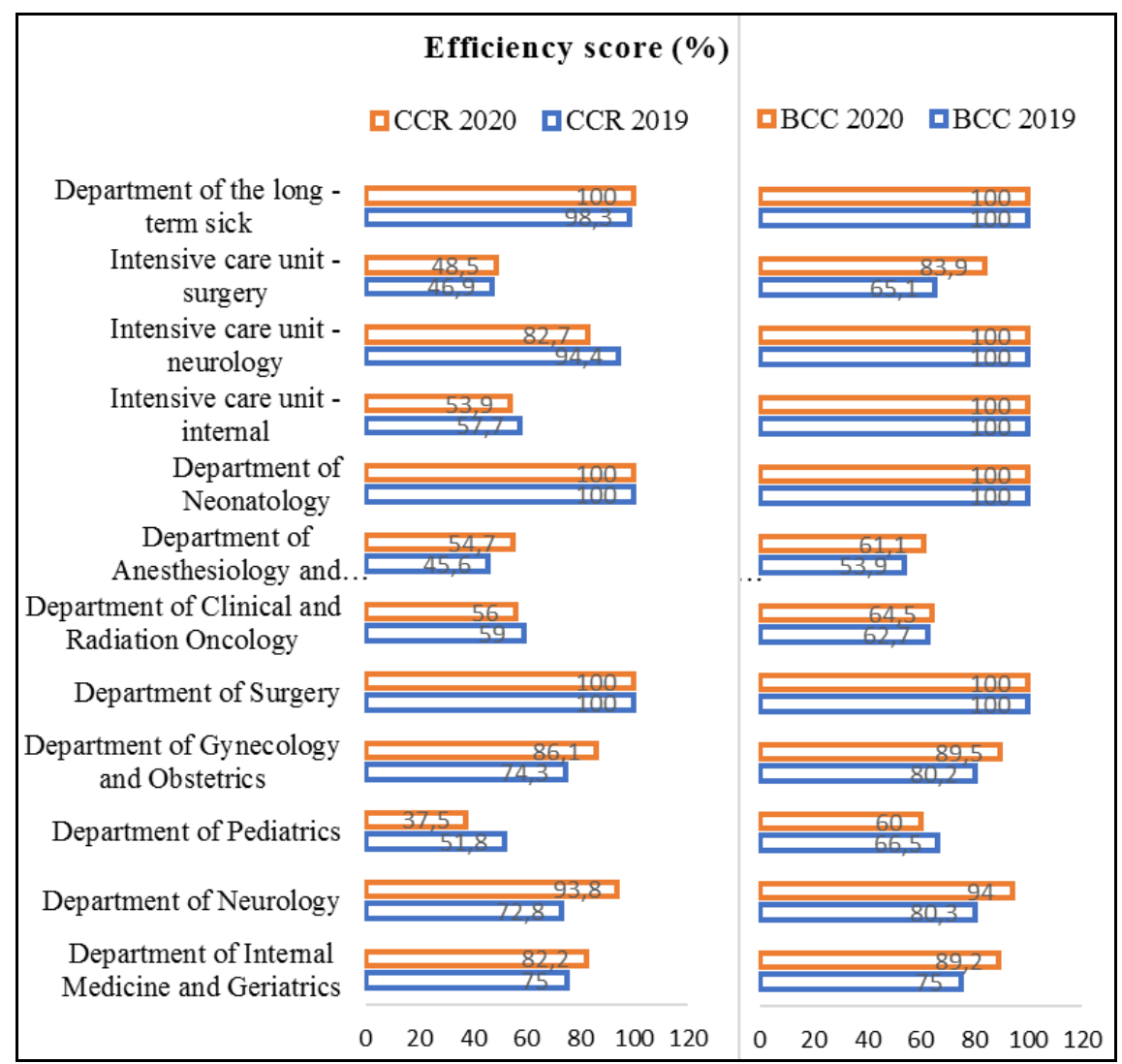

Figure 1. Comparison of efficient scores Source: author's own research

It can be seen from Table 2 and Figure 1 that the Department of Neonatology and Department of Surgery reported the best efficiency scores in 2019 in both models. According to the BCC model, efficiency of $100 \%$ was also reached by the Department of the long-term sick and Intensive care unit - neurology and internal. According to both models, three departments, namely the Department of Surgery, Department of Neonatology, and Department of the long-term sick had reached the efficiency of $100 \%$ in 2020 . The efficiency of the Department of the longterm sick rose by $1.7 \%$ in CCR model. The highest efficiency increase was found to be in the Department of Neurology (CCR model: 21\%; BCC model: 13.7\%). According to the BCC model, the highest efficiency increase was identified in the Intensive care unit - surgery whereas the increase of $1.6 \%$ was identified in CCR model. The highest average efficiency improvement of $17.6 \%$ was recorded in the Department of Neurology. The number of doctors and nurses decreased, costs between 2019 and 2020 increased by $€ 104,854$, yet the revenue increased by $€ 406,619$. This is, however, a simplistic quantitative view, and as aforementioned, it is not always ethical to discuss hospital staff cutbacks from the perspective of health care.

Ten inefficient wards were identified by the CCR model in 2019 and nine wards in 2020. BCC model identified seven inefficient departments in 2019 and 2020 respectively. According to both models, the most inefficient was found to be the Department of Paediatrics. The drop in the efficiency score between 2019 and 2020 was 14.3\%; the BCC model indicated a decline of $6.5 \%$. The headcount remained unchanged in both analysed years; input costs increased by $€ 62,184$; revenue decreased by $€ 96,848$. It is to be attributed to the minimum legally required staffing of the department, despite a declining number of paediatric hospital admissions in the region. 
The average efficiency increased between 2019 and 2020 in both models. In the resulting DEAOS reports, input reductions were suggested because input-oriented models were used. The actual situation in 2019 and the suggested input indicator reductions according to $\mathrm{BCC}$ model are given below. In addition, the data on the actual situation in 2020 and efficient score changes listed in the table 3 below.

Table 3. Proposed reduction of inputs

\begin{tabular}{|c|c|c|c|c|c|c|c|c|c|}
\hline \multirow[b]{3}{*}{$D M U$} & \multicolumn{5}{|c|}{ BCC 2019} & \multirow{2}{*}{\multicolumn{3}{|c|}{ Situation in 2020}} & \multirow{3}{*}{$\begin{array}{l}\text { Change in the } \\
\text { efficient score }\end{array}$} \\
\hline & \multicolumn{2}{|c|}{ Doctors } & \multicolumn{2}{|c|}{ Nurse } & \multirow[b]{2}{*}{$\Delta$ costs } & & & & \\
\hline & from & To & from & To & & doctors & Nurse & $\Delta$ costs & \\
\hline 1 & 13 & 10 & 23 & 18 & $-716,006$ & 12 & 23 & 420,579 & 14.2 \\
\hline 2 & 8 & 4 & 15 & 13 & $-197,290$ & 6 & 14 & 104,854 & 13.7 \\
\hline 3 & 5 & 2 & 11 & 8 & $-238,632$ & 5 & 11 & 62,183 & -6.5 \\
\hline 4 & 11 & 5 & 16 & 13 & $-225,452$ & 11 & 16 & 62,344 & 9.3 \\
\hline 5 & 12 & 12 & 20 & 20 & 0 & 14 & 20 & 91,102 & 0 \\
\hline 6 & 4 & 3 & 11 & 7 & $-317,489$ & 5 & 11 & 128,746 & 1.8 \\
\hline 7 & 8 & 3 & 19 & 11 & $-499,994$ & 9 & 18 & 160,341 & 7.2 \\
\hline 8 & 1 & 1 & 11 & 11 & 0 & 1 & 11 & 55,907 & 0 \\
\hline 9 & 1 & 1 & 10 & 10 & $-164,870$ & 1 & 11 & 47,148 & 0 \\
\hline 10 & 1 & 1 & 5 & 5 & 0 & 2 & 4 & 137,662 & 0 \\
\hline 11 & 2 & 1 & 10 & 5 & $-175,276$ & 2 & 9 & 55,488 & 18.8 \\
\hline 12 & 2 & 2 & 8 & 8 & 0 & 2 & 8 & 62,273 & 0 \\
\hline
\end{tabular}

The Table 3 shows that the total costs increased for all the wards in 2020. This is linked to the increased costs for personal protective equipment in the context of the Covid-19 pandemic. The costs were compensated by the Ministry of Health. Thus, the reduction in the costs input indicator was not necessary.

\section{Conclusions}

DEA is one of the essential methods used in research and economics. It can be employed to evaluate the efficiency of individual producers within a given group. Compared to other methods, DEA is a relatively new non-parametric method. It is one of the methods used to assess the efficiency, performance and productivity of homogeneous production units. Homogeneity of production unit means that the units are engaged in the production of identical or equivalent outputs. In the process of production, they consume identical or equivalent inputs. DEA allows an individual evaluation of the production unit efficiency relative to the whole set of units. In addition to identifying efficient and inefficient units, DEA identifies sources of efficiency as well as reductions or extensions needed to achieve efficiency.

DEA is used to measure and compare efficiency of production units in different areas. Efficiency is measured by comparing inputs and outputs. In the case of health care institutions, DEA evaluates efficiency of input transformation into outputs in health care services. DEA is one of the operational research methods used to 


\section{ENTREPRENEURSHIP AND SUSTAINABILITY ISSUES}

ISSN 2345-0282 (online) http://jssidoi.org/jesi/ 2021 Volume 9 Number 1 (September) http://doi.org/10.9770/jesi.2021.9.1(27)

optimize inputs or outputs. Poor quality of health care services often goes hand in hand with inefficient financial management. To put it differently, disproportionate resource increases lead to wasting resources and lower quality of health care services.

In the study, wards in a medium-sized private hospital in Slovakia were assessed. In this case, economic performance is closely watched and evaluated by the hospital shareholder. Quality health care services are, without doubt, the primary mission of the hospital. 12 inpatient wards in 2019 and 2020 were assessed using DEA models. Input indicators were labour costs, number of doctors, and number of nurses. Capital inputs were represented by total costs per department. Costs were made up of several components. In the DEA models used, revenues, i.e. capital output, were evaluated as an output indicator. Two basic DEA models, constant returns to scale and variable returns to scale, were utilised. The purpose of the research was to identify inefficient wards and suggest cost reductions since the models were input-oriented. However, much of the resource reduction is not possible due to legal norms on staffing.

Since this was a pilot study, it was not possible to compare its findings with the outcomes of similar DEA analyses in other hospitals. Therefore, this can be considered to be a new model for assessing the health care efficiency in the wards of other hospitals. To improve the proposed DEA model, more experts, especially hospital managers, should be involved in the discussion as the study is mainly focused on the assessment of financial efficiency.

The hospital management consider the methods used in the study to be an option for continual efficiency assessment of the wards. It is, however, necessary to work with other inputs, such as occupancy rates, adjusting the number of beds to staffing norms in individual wards, diagnose weights (Case Mix Index), etc. Outputs should include, for example, the average length of hospital stay and other measurable factors.

\section{References}

Andes, S., Metzger L. M., Kralewski, J., Gans, D. (2002). Measuring efficiency of physician practices using data envelopment analysis. National Library of Medicine, 11 (11), 48-54. PMID: 12491859. Retrieved May 10, 2021 from URL

https://europepmc.org/article/med/12491859

Arya, A., Yadav, S. P. (2018). Development of intuitionistic fuzzy super-efficiency slack based measure with an application to health sector. Computers \& Industrial Engineering, 115, 369-380. https://doi.org/10.1016/j.cie.2017.11.028.

Banker, R. D., Charnes, A., Cooper, W. W. (1984). Some Models for Estimating Technical and Scale Inefficiencies in Data Envelopment Analysis. Management Science, 30 (9), 1078-1092. https://doi.org/10.1287/mnsc.30.9.1078

Barnum, D. T., Walton, S. M., Shields, K. L.,Schumock, G. T. (2011). Measuring Hospital Efficiency with Data Envelopment Anylysis: Nonsubstitutable vs. Substitutable Inputs and Outputs. Journal of Medical Systems. 1-22. https://doi.org/10.1007/s10916-009-9416-0

Belciug, S., Gorunescu, F. (2016). A hybrid genetic algorithm-queuing multi-compartment model for optimizing inpatient bed occupancy and associated costs. Artificial Intelligence in Medicine, (68), 59-69. https://doi.org/10.1016/j.artmed.2016.03.001

Caballer-Tarazona, M., Moya-Clemente, I., Vivas-Consuelo, D., Barrachina-Martínez, I. (2010). A model to measure the efficiency of hospital Performance. Mathematical and Computer Modelling, 52, 1095-1102. https://doi.org/10.1016/j.mcm.2010.03.006

Cesconetto, A., Dos Santos Lapa, J., Marino Calvo M. C. (2008). Evaluation of productive efficiency in the Unified National Health System hospitals in the State of Santa Catarina, Brazil. CSP Reports in Public Health, 24 (10), 2407-2417. https://doi.org/10.1590/S0102$\underline{311 \times 2008001000021}$

Charnes, A., Cooper, W. W., Rhodes, E. (1978). Measuring the Efficiency of Decision Making Units. European Journal of Operational Research, 2 (6), 429-444. https://doi.org/10.1016/0377-2217(78)90138-8 


\section{ENTREPRENEURSHIP AND SUSTAINABILITY ISSUES}

ISSN 2345-0282 (online) http://jssidoi.org/jesi/ 2021 Volume 9 Number 1 (September)

http://doi.org/10.9770/jesi.2021.9.1(27)

Cheng, Z., Cai, M., Tao, H., et al. (2016). Efficiency and productivity measurement of rural township hospitals in China: a bootstrapping data envelopment analysis. BMJ Open 2016; 6:e011911. https://doi.org/10.1136/bmjopen-2016-011911

Coelli T. (1996) A Guide to DEAP Version 2.1: A data envelopment analysis (computer) program. Center for Efficiency and Productivity Analysis University of New England. Working paper. 96 (08). Retrieved May 10, 2021 from URL: http://www.owlnet.rice.edu/ econ380/DEAP.PDF

Czypionka, T., Kraus, M., Mayer, S., Röhrling, G. (2014). Efficiency, Ownership, and Financing of Hospitals: The Case of Austria. Health Care Management Science, 17 (4), 331-347. https://doi.org/10.1007/s10729-013-9256-9

Data Envelopment Analysis Online Software https://www.deaos.com/en-us/product/Product/0004/DEA-and-Health-Care

Dy, S. M., Kiley, K. B., Ast, K., et al. (2015). Measuring What Matters: Top-Ranked Quality Indicators for Hospice and Palliative Care From the American Academy of Hospice and Palliative Medicine and Hospice and Palliative Nurses Association. Journal of Pain and Symptom Management, 49 (4), 773-781. https://doi.org/10.1016/j.jpainsymman.2015.01.012.

De Souza A. A., Avelar E. A., Moreira, D. R., De Faria Marques A. M. (2014). Data envelopment analysis of efficiency in hospital organisations. International Journal of Bussiness Innovation and Research, 8 (3), 316-332. https://doi.org/10.1504/LIBR.2014.060831

Farrell, M. J. (1957). Measuremnt of Productive Efficiency. Journal of the Royal Statistical Society, 120 (3), 253-290. https://doi.org/10.2307/2343100

Giuffrida, A., Gravelle, H. (2010). Measuring Performance in Primary Care: Econometric Analysis and DEA. Applied Economics, 33 (2). 163-175. Retrieved May 19, 2021 from URL https://www.tandfonline.com/doi/abs/10.1080/00036840122522

Grmanová, E. (2010). Hodnotenie efektívnosti komerčných poistovní a bánk modelmi analýzy obalu dát. Trenčín: FSEV TnUAD.

Hollingsworth, B. (2008). The measurement of efficiency and productivity of health care delivery. Health Economics 17 (10), $1107-1128$. https://doi.org/10.1002/hec.1391

Jablonský, J. (2015). Efficiency analysis in multi-period systems: an application to performance evaluation in Czech higher education. CEJOR 24, 283-296 Springer-Verlag Berlin Heidelberg. https://doi.org/10.1007/s10100-015-0401-z

Jablonský, J., Dlouhý, M. (2004). Modely hodnoceni efektívnosti produkčných jednotek. Praha: Professional publishing

Kališ, R. (2018). Technical efficiency of Slovak general hospitals. University of Economics in Bratislava, Department of Economic Policy Working Paper Series, 12, 1-14. Retrieved May 11, 2021 from URL https://www.econstor.eu/bitstream/10419/201206/1/dep wp012.pdf

Kohl, S., Schoenfelder, J., Fügener, A. et al. (2019). The use of Data Envelopment Analysis (DEA) in healthcare with a focus on hospitals. Health Care Manag Sci, 22, 245-286. https://doi.org/10.1007/s10729-018-9436-8

Kocisova, K., Gavurova, B., Behun, M. (2019). The Importance of Implementing Environmental Variables in the Process of Assessment of Healthcare Efficiency through DEA. Ekonomický časopis, 67 (4), 367-387. Retrieved May 21, 2021 from URL https://www.ceeol.com/search/article-detail?id=780781

Kuntz L, Scholtes S, Vera A. (2007). Incorporating efficiency in hospital-capacity planning in Germany. Eur J Health Econ. 8 (3), $213-23$. https://doi.org/10.1007/s10198-006-0021-6

Lacko, R., Bosakova, L., Kubak, M., Nemec, J., Tkac, M. (2014). Technical Efficiency of Selected Private Hospitals in Slovakia. In: Proceedings of the 18th International Conference on Current Trends i Public Sector Research. Brno: Masaryk University, $269-275$.

Linna, M. (1998). Measuring hospital cost efficiency with panel data models. Health Economics, 7 (5), $415-427$. https://doi.org/10.1002/(SICI)1099-1050(199808)

Maniadakis, N., Thanassoulis, E. (2000). Assessing Productivity Changes in UK Hospitals reflecting Technology and Input Prices. Applied Economics, 32 (12), 1575-1589. https://doi.org/10.1080/000368400418970

Mura, L., Orlikova, M. (2016). Social Entrepreneurship and Social Enterprises: The Case of Slovakia. In: Proceedings of the 4th International Conference Innovation Management. Entrepreneurship and Corporate Sustainability. Prague: University of Economics, 495505. 


\section{ENTREPRENEURSHIP AND SUSTAINABILITY ISSUES}

ISSN 2345-0282 (online) http://jssidoi.org/jesi/ 2021 Volume 9 Number 1 (September) http://doi.org/10.9770/jesi.2021.9.1(27)

Nunamaker, T. R. (1983). Measuring routine nursing service efficiency: a comparison of cost per patient day and data envelopment analysis models. Health Services Research, 18 (2), 183-208. Retrieved May 21, 2021 from URL https://www.ncbi.nlm.nih.gov/pmc/articles/PMC1068745/

Oikonomou, N., Tountas, Y., Mariolis, A. et al. (2016). Measuring the efficiency of the Greek rural primary health care using a restricted DEA model; the case of southern and western Greece. Health Care Manag Sci 19, 313-325. https://doi.org/10.1007/s10729-015-9324-4

Sellers-Rubio, R., Casado-Díaz, A. B. (2018). Analyzing hotel efficiency from a regional perspective: The role of environmental determinants. International Journal of Hospitality Management, 75, 75-85. https://doi.org/10.1016/j.ijhm.2018.03.015.

Sebetci, Ö., Uysal, I. (2017). The Efficiency of Clinical Departments in Medical Faculty Hospitals: A case Study Based on Data Envelopment Analysis. International Journal of Computer Sciences and Engineering, 1-8. https://doi.org/10.26438/ijcse/v517.18

Sherman, H. D. (1984). Hospital efficiency measurement and evaluation. Empirical test of e new technique. Med. care, 22 (10), $922-938$. Retrieved May 21, 2021 from URL https://www.jstor.org/stable/3764490?seq=1

Shetabi, H., Safi-Keykaleh, M., Nasiripour, A. A., Mohammadi, M. (2015). Evaluating technical efficiency of Kermanshah city universities by means data envelopment analysis model. Research Journal of Mesdical Sciences, 9 (3), 53-57. https://doi.org/10.3923/rjmsci.2015.53.57

Stefko, R., Gavurova, B., Kocisova, K. (2018). Healthcare efficiency assessment using DEA analysis in the Slovak Republic. Health Economics Review, 8 (6), 1-12. https://doi.org/10.1186/s13561-018-0191-9

Varabyova, Y., Schreyögg. (2013). International Comparsions of the Technical Efficiency of the Hospital Sector: Panel Data Analysis of OECD Countries Using Parametric and Non-Parametric Approaches. Health policy, 112, 70-79. https://doi.org/10.1016/j.healthpol.2013.03.003

Worthington, A. (2004). Frontier Efficiency Measurement in Healthcare: A Review of Empirical Techniques and Selected Applications. Medical Care Research and Review 61 (2), 1-36. https://doi.org/10.1177/1077558704263796

Yaisawarng, S. (2002). Performance Measurement and Resource Allocation. In: Fox K.J. (eds) Efficiency in the Public Sector. Studies in Productivity and Efficiency, vol 1. Springer, Boston, MA. https://doi.org/10.1007/978-1-4757-3592-5 4

\section{Acknowledgements}

This research was supported by the Slovak Research and Development Agency under the contract No. APVV-19-0579.

Dana JAŠKOVÁ is the Assistent Professor at Department of Economy and Economics, Faculty of Social and Economic Relations, Alexander Dubček University in Trenčín. She has long been involved in the research and application of mathematics and statistics in economics and management

ORCID ID: orcid.org/0000-0002-7250-9207 